\title{
Efficacy of Endoscopic Ultrasonography in Evaluation of Undetermined Etiology of Common Bile Duct Dilatation on Abdominal Ultrasonography
}

\author{
Rasoul Sotoudehmanesh ${ }^{1 *}$, Naimeh Nejati ${ }^{2}$, Maryam Farsinejad ${ }^{3}$, Shadi Kolahdoozan ${ }^{3}$
}

\section{ABSTRACT}

1. Professor. Digestive Disease Research Institute, Shariati Hospital, Tehran University of Medical Sciences, Tehran,Iran

2. Gastroenterologist. Baghyatallah hospital, Tehran,Iran

3. Research Fellow. Digestive Disease Research Institute, Shariati Hospital, Tehran University of Medical Sciences, Tehran,Iran

\footnotetext{
* Corresponding Author:

Rasoul Sotoudehmanesh, MD

Digestive Disease Research Institute, Shariati Hospital, North Kargar Ave., Tehran, Iran Postal code: $41448-95655$

Tel: + 982182415300

Fax: + 982182415400

Email: sotoudehmanesh@tums.ac.ir

Received: 11 Apr. 2016

Accepted: 02 Sep. 2016
}

\section{BACKGROUND}

The cause of common bile duct (CBD) dilatation cannot be determined by imaging modalities in many patients. The aim of this study was to assess the value of endoscopic ultrasonography (EUS) in detecting the cause of CBD dilatation in patients in whom ultrasonography could not demonstrate the cause of dilation.

\section{METHODS}

Prospectively, 152 consecutive patients who were referred for evaluation of dilated CBD (diameter $\geq 7 \mathrm{~mm}$ ) of undetermined origin by ultrasonography were included in this study. All the patients underwent EUS. Final diagnoses were determined by using endoscopic retrograde cholangiopancreatography (ERCP), EUS-guided fine needle aspiration (FNA), surgical exploration, or follow-up for at least 10 months. Patients with choledocholithiasis were referred for ERCP and sphincterotomy, and patients with operable tumors were referred for surgery. Patients with inoperable tumors underwent biliary stenting with or without chemoradiotherapy.

\section{RESULTS}

152 patients ( $54 \%$ female) with dilated CBD were included. Mean $( \pm \mathrm{SD})$ age of the patients was $60.4( \pm 17.3)$ years. The mean CBD diameter for all study group in transabdominal ultrasonography and EUS were 11.7 millimeter and 10.1 millimeter, respectively. Most of the patients with dilated CBD and abnormal liver function test (LFT) had an important finding in EUS and follow-up diagnosis including peri-ampullary tumors. Mean diameter of CBD in patients with and without abnormal LFT were $10.5 \mathrm{IU} / \mathrm{L}$ and $12.1 \mathrm{IU} / \mathrm{L}$, respectively. Final diagnoses included choledocholithiasis in $32(21.1 \%)$, passed CBD stone in 35 (23\%), opium-induced CBD dilation in $14(9.2 \%)$, post-cholecystectomy states in $20(13.1 \%)$, ampullary adenoma/carcinoma in $15(15.8 \%)$, cholangiocarcinoma in $14(9.2 \%)$, and pancreatic head cancer in $9(5.9 \%)$ patients. Sensitivity, specificity, positive predictive value, negative predictive value and accuracy of EUS for patients with abnormal EUS were $89.5 \%, 100.0 \%, 100.0 \%, 91.2 \%$, and $90.9 \%$, respectively.

\section{CONCLUSION}

After diagnosis of CBD dilation by transabdominal ultrasonography, EUS may be a reasonable choice for determining the etiology of dilated CBD and tumor staging.

KEYWORDS:Diagnosis, Endosonography, Common bile duct, Ampulla of Vater

\section{Please cite this paper as:}

Sotoudehmanesh R, Nejati N, Farsinejad M, Kolahdoozan S . Efficacy of Endoscopic U1trasonography in Evaluation of Undetermined Etiology of Common Bile Duct Dilatation on Abdominal Ultrasonography. Middle East J Dig Dis 2016;8:267-272. DOI :10.15171/ mejdd.2016.35 


\section{INTRODUCTION}

Common bile duct (CBD) dilation on imaging modalities, such as transabdominal ultrasonography (TUS), computed tomography (CT), and magnetic resonance cholangiopancreatography (MRCP) is a common challenging issue in daily practice. TUS should be the first imaging study in evaluation the level of biliary obstruction and gallstones. However, overlying bowel gas and obesity frequently obscure the distal bile duct, ampulla, and pancreas. Thus determining the etiology of CBD dilation by TUS alone is usually impossible.

The diagnostic evaluation of a patient with a bile duct obstruction is designed to differentiate benign lesions such as gallstones from the malignant biliary obstruction and to establish the extent of tumor invasion and spread in cases with malignancy.

Endoscopic retrograde cholangiopancreatography (ERCP) has been the gold standard for evaluation of the pancreatobiliary disorders. ${ }^{1,2}$ However, it is associated with complications especially pancreatitis. ${ }^{3,4}$ For this reason, less invasive and high accurate diagnostic modalities such as endoscopic ultrasound (EUS) or MRCP are recommended for most suspected periampullary lesions. ${ }^{5}$

In case of isolated dilated CBD on TUS, there is no clear clinical guideline for further evaluation. Therefore we prospectively evaluated the role of EUS in detecting the cause of CBD dilatation in patients in whom TUS could not demonstrate the cause of dilation.

\section{MATERIALS AND METHODS}

Between June 2013 and September 2014, we prospectively evaluated individuals who were referred to the endoscopy ward of a referral university-affiliated hospital because of dilated CBD on TUS.

The inclusion criteria were; 1) Internal diameter of $\mathrm{CBD} \geq 7 \mathrm{~mm}, 2$ ) no causative lesion in TUS. Exclusion criteria were history of surgery with gastroenteric anastomosis (Roux-en-Y gastrojejunostomy or Whipple's procedure), which made a successful EUS and ERCP unlikely and refusal of giving written informed consent.

Abnormal liver function test (LFT) was defined as AST(aspartate aminotransferase) or ALT(alanine aminotransferase) more than $40 \mathrm{IU} / \mathrm{L}$ and or alkaline phosphatase more than $306 \mathrm{IU} / \mathrm{L}$. Weight loss was defined as un- intentional loss of weight more than $10 \%$ over 10 months.

All EUS procedures were performed with a radial echoendoscope (EG-3630UR, PENTAX Optical Co Ltd, Tokyo-Japan). In case of suspected ampullary mass based on the EUS exam and if it was not adequately visualized by endoscopic view, a duodenoscope (ED-3470TK, Pentax Medical Co.) was used to view the ampulla of Vater and obtain biopsy samples in case of ampullary masses. Whenever we found a lesion in the pancreas requiring tissue diagnosis, we performed EUS-fine needle aspiration (FNA) using a convex array echoendoscope (Pentax EG-3830 UT). All FNAs were performed with a 22-gauge needle (Echotip; Wilson- Cook, Winston Salem, NC). All data regarding the patients' age, sex, complaints, results previous laboratory tests and images, primary indications of EUS, the incidental findings and their locations, size, and origin were recorded in a standard questionnaire. The patients were finally divided in to four major groups: The patients with operable periampullary neoplasms who were referred for surgery, the patients with inoperable periampullary tumors who underwent ERCP and biliary stenting and referred to oncologist, the patients with bile duct stone who were referred for ERCP and sphincterotomy for stone extraction, and the patients with normal pancreatobiliary tract.

Gold standards in this study were ERCP, surgery, a biopsy confirming malignancy, or the clinical course during follow-up (at least 10 months) in cases without evidence of malignancy by clinical visits or phone calls. The study was approved by the Institutional Review Board of the Digestive Diseases Research Institute of Tehran University of Medical Sciences. Written informed consent was obtained according to the guidelines of the institute. Quantitative variables were presented as mean \pm standard deviation (SD). Sensitivity, specificity, positive and negative predictive values (PPV, and NPV) and accuracy were calculated using the standard formulas. The target conditions considered for statistical analysis were: correct diagnosis of any cause of obstruction, diagnosis of malignancy, or the diagnosis of CBD stone. All calculations were performed using SPSS software, version 20 (SPSS Inc.; Chicago, Illinois, USA).

\section{RESULTS}


Table 1: Baseline characteristics of patients with common bile duct dilation in transabdominal ultrasonography

\begin{tabular}{lccc}
\hline Variables & Total & Normal LFT & Abnormal LFT \\
\hline Age (year); mean (SD) & $60.4 \pm 17.7$ & $56.4 \pm 18.5$ & $61.34 \pm 17.8$ \\
\hline Female; N (\%) & $82(53.9)$ & $19(70.4)$ & $53(49.5)$ \\
\hline Opium addiction; N (\%) & $25(16.4)$ & $7(25.9)$ & $15(14.4)$ \\
\hline Previous cholecystectomy; N (\%) & $34(22.4)$ & $10(37.0)$ & $21(19.6)$ \\
\hline Disease duration (month); mean (SD) & $4.9(11.1)$ & $9.7 \pm 15.7$ & $3.22(6.8)$ \\
\hline Abdominal pain; N (\%) & $118(77.6)$ & $25(92.6)$ & $78(72.9)$ \\
\hline Weight loss; N (\%) & $41(27)$ & $3(11.1)$ & $34(31.8)$ \\
\hline Jaundice; N (\%) & $61(40)$ & $0(0.0)$ & $56(52.3)$ \\
\hline Abnormal liver tests; N (\%) & $125(82.2)$ & -- \\
\hline Bilirubin(mg/dL); mean (SD) & $6.1(7.6)$ & $0.8 \pm 0.3$ & $7.3(7.9)$ \\
\hline CBD diameter by ultrasonography(mm); mean (SD) & $11.7(4.1)$ & $10.5 \pm 2.9$ & $12.1(4.4)$ \\
\hline GB stone; N (\%) & $50(33)$ & $4(14.8)$ & $42(39.3)$ \\
\hline Performed CT; N (\%) & $49(32)$ & $7(25.9)$ & $36(33.6)$ \\
\hline Performed MRI/MRCP; N (\%) & $68(45)$ & $15(55.6)$ & $46(43.0)$ \\
\hline
\end{tabular}

Common bile duct; mm: Millimeter; SD: Standard deviation; N: Number; GB: Gallbladder; CT: Computerized tomography; MRCP: Magnetic resonance cholangiopancreatography; MRI: Magnetic resonance imaging

During the study period 922 patients underwent EUS. 152 consecutive patients with an enlarged CBD (diameter $\geq 7$ millimeter) of undetermined origin during TUS were included in this study. The patients' characteristics and EUS findings are summarized in table 1. The mean age of the patients was 60.4 year (range $=22-90$ year). Most of the patients were female (53.9\%). EUS exams were done without difficulty or complications. 27 patients (17.8\%) had normal LFT (table 2). The mean CBD diameter for all cases in TUS and EUS groups were 11.7 $\mathrm{mm}$ and $10.1 \mathrm{~mm}$ respectively.13 (8.5\%) patients in our study had "normal" findings in EUS. In patients with abnormal LFT, significant findings included: 26 cases of CBD stone, 14 cases of ampullary tumor, 10 with distal CBD tumor, and 8 pancreatic tumors. 68 patients had CBD dilatation in MRCP with unknown etiology. Only 2 of them had a "normal" EUS. Of the remaining 66 patients, 64 had findings consistent with CBD stone/ sludge. Five patients (7.8\%) underwent ERCP with endoscopic sphincterotomy and stone extraction. 20 patients (31.3\%) passed CBD stone with normal LFT and normal clinical findings at follow-up visits. Three patients $(4.7 \%)$ had pancreatic mass for whom EUS-FNA was done, which showed operable mass in two patients. Seven patients $(10.9 \%)$ had ampullary tumor for whom biopsy sampling was done by side-view duodenoscope, which showed operable tumor in five patients. Seven patients (11\%) had distal CBD tumor, which were operable in all of them. Post cholecystectomy CBD dilation was seen in nine patients (14.1\%), opium related CBD dilation was seen in nine patients (14.1\%), juxta-ampullary diverticulum in one patient (1.6\%), and gallbladder (GB) stone alone was seen in three patients (4.7\%).

Table 3 shows the final diagnosis of patients with dilated CBD. For two patients with pancreatic tumor, seven patients with ampullary tumor, six patients with distal CBD tumor, and finally eight patients with CBD stone, MRI/MRCP was performed, which showed no abnormality except for CBD dilation. At the other hand, for four patients with pancreatic tumor, 11 patients with ampullary tumor, five patients with distal CBD tumor, and finally 11 patients with CBD stone, abdominal CT was performed, which showed no abnormality except for CBD dilation.

Overall sensitivity, specificity, PPV, NPV, and accuracy of EUS were $93.8 \%, 100.0 \%, 98.1 \%, 100.0 \%$, and $90.1 \%$, respectively. Sensitivity, specificity, PPV, NPV and accuracy of EUS for patients with abnormal EUS were $89.5 \%, 100.0 \%, 100.0 \%, 91.2 \%$, and $90.9 \%$, respectively. 
Table 2: Diagnosis in patients with normal liver function test

\begin{tabular}{lc}
\hline Variables & N. (\%) \\
\hline Normal & $5(18.5)$ \\
\hline CBD stone/Sludge & $2(7.4)$ \\
\hline Passed CBD stone & $5(18.5)$ \\
\hline Opium induced CBD dilation & $6(22.2)$ \\
\hline Post cholecystectomy state & $8(29.6)$ \\
\hline GB stone & $1(3.7)$ \\
\hline CBD: common bile duct; GB: gallbladder; N: number.
\end{tabular}

Table 3: Final diagnosis of patients with dilated CBD

\begin{tabular}{lc}
\hline Benign disorders & N. (\%) \\
\hline Choledocholithiasis & $32(21.0)$ \\
\hline Post-cholecystectomy & $20(13.1)$ \\
\hline Opium addiction & $14(9.2)$ \\
\hline Passed CBD stone & $35(23.0)$ \\
\hline Malignant disorders & \\
\multicolumn{1}{c}{ Ampulla of Vater } \\
\multicolumn{1}{c}{ Pancreas tumor CBD tumor } & $15(9.8)$ \\
\hline Normal CBD & $14(9.2)$ \\
\hline Total & $9(5.9)$ \\
\hline CBD: Common bile duct; N: Number & $13(8.5)$ \\
\hline
\end{tabular}

DISCUSSION

In daily practice there are no clear clinical guidelines regarding further evaluation of patients with a clinical suspicion of periampullary lesions in the absence of an obvious lesion on transabdominal imaging. Our study shows the significant impact of EUS in the diagnosis of benign as well as periampullary tumors when other imaging modalities failed to show the etiology.

Differentiating a primary ampullary carcinoma from the more common periampullary malignancies (arising in the pancreas, duodenum, or bile duct) is challenging. Sometimes it is impossible to determine the exact location and definite diagnosis of periampullary neoplasm until resection and histopathological evaluation of the entire surgical specimen is completed. ${ }^{6}$ The most common cause of CBD dilation of our patients was periampullary malignant tumors found in 38 cases (25\% of the patients). These included tumor of the papilla of the Vater in 15 patients, cholangiocarcinoma in 14, and pancreas head cancer in 9 cases. This is an important finding that shows relative inability of other imaging modalities for detection of these tumors.

In studies of patients with pancreatic cancer, EUS has been superior to CT for the diagnosis of pancreatic cancer. ${ }^{7,8}$ Thus pancreatic masses diagnosed by EUS, can be missed by TUS and CT.

The overall accuracy of TUS for detection of ampullary tumor was $15 \%$, according to one study. ${ }^{9}$

In our study, one-third of the patients performed CT. The cause of CBD dilation could not be determined in four patients who performed abdominal CT. CT is more sensitive than TUS for evaluating the periampullary region. Although helical CT can detect masses obstructing the distal $\mathrm{CBD}$, its sensitivity for detection of small periampullary lesions is low. ${ }^{10}$ Moreover, although CT is generally the most useful modality to evaluate the presence of distant metastatic disease, which most frequently involves the regional lymph nodes, liver, peritoneum, lungs, and bone, its overall accuracy was only $20 \%$ for detection of periampullary lesions. ${ }^{9}$ Especially for the ampullary tumor staging, the accuracy of $\mathrm{CT}$ is very low because it cannot determine the depth of the ampullary tumor, definite extension of the lesion toward the adjacent organs like duodenal wall and pancreas tissue or major vascular involvement. ${ }^{11} \mathrm{MRCP}$ is a non-invasive method of imaging the pancreaticobiliary tree via MRI. Ampullary carcinomas appear as masses (filling defects) protruding into the duodenal lumen, with characteristic delayed enhancement. ${ }^{12}$ In one report the overall accuracy of diagnosis with MRCP was $76 \%{ }^{13}$

MRI/MRCP is very poor for imaging the periampullary neoplasms and many MRI/MRCP Reports, which show an unexplained dilated bile duct inevitably read "cannot exclude peri-ampullary pathology/neoplasia". ${ }^{14}$ In our study $45 \%$ of the patients underwent MRI/MRCP, which only revealed CBD dilation. Of these patients, 17 had periampullary tumors, which showed that in more than one-fourth of the patients MRI/MRCP could not detect the tumors.

The second most common cause of CBD dilation in our study was passed CBD stone, which occurred in 35 patients $(23 \%)$. These patients presented with colicky abdominal pain relieved at the time of EUS examination. Basis of diagnosis was normalization of LFT after biliary colic, the presence of stone in gall bladder, and lack of symptoms during the 10-month follow up after cholecystectomy and normal LFT. 
We found that most of the patients with dilated CBD and abnormal LFT had an important finding in EUS and follow up diagnosis. As shown in table 2 all of the patients with normal LFT had benign conditions. In other word, all of the patients with malignant periampullary lesions had abnormal LFT. This finding has been shown in other studies. ${ }^{15-17}$ Choledocholithiasis was found in $32(21 \%)$ of our cases. MRCP and CT were done in 8 (44.4\%) and $11(61.1 \%)$ of these patients respectively, which did not reveal the diagnosis. The sensitivity of TUS for CBD stones ranges from $20 \%$ to $90 \%$. TUS has poor sensitivity for stones in the distal CBD because the distal CBD is often obscured by bowel gas in the imaging field. ${ }^{18,19} \mathrm{~A}$ review of 13 studies found that MRCP had a sensitivity of $93 \%$ and a specificity of $94 \%$ for the diagnosis of choledocholithiasis. ${ }^{20}$ Abdominal CT and percutaneous cholangiopancreatography are alternative methods for diagnosis of choledocholithiasis.

Both sensitivity and specificity of abdominal CT can be improved from $65 \%$ to $93 \%$ and from $84 \%$ to $100 \%$, respectively by the use of intravenous contrast media combined with a helical cholangiography protocol. ${ }^{21,22}$

Other interesting finding in our study was opium induced CBD dilation found in $14(9.2 \%)$ patients. This finding has been shown by other studies. ${ }^{23,24}$ Mechanism of CBD dilatation in opium addicted cases is the effects of morphine on sphincter of Oddi. Morphine causes increase in basic pressure and the range and the frequency of phasic contractions of the sphincter of Oddi.

The combination of these effects leads to CBD dilatation by increasing the CBD internal pressure. ${ }^{23}$ In the presence of biliary colic, endoscopic sphincterotomy results in relieving symptoms. ${ }^{25}$

The limitation of our study was that the TUS, MRI/ MRCP, and CTs (obtained before EUS) were not standardized with regard to technique and interpretation. It could be possible that the interpretation of some of the images would have changed if another radiologist had reviewed the images.

Other limitation of our study is that CT and MRI/ MRCP were not done for all the patients with CBD dilation. This was due to the fact that the patients who were referred to our ward for EUS had already performed their imaging studies and we could not refer them for extra imaging study before EUS.

In conclusion, EUS is a complementary imaging modality after TUS for evaluation of dilated CBD and has an important role in the diagnosis of benign and malignant periampullary tumors with high sensitivity and specificity. Although other studies should confirm our findings, we suggest EUS after detecting CBD dilation by TUS, for diagnosis, staging, and sampling (in cases with neoplastic process) of the lesions. These benefits may not be achieved easily and with high accuracy by other imaging modalities.

\section{CONFLICT OF INTEREST}

The authors declare no conflict of interest related to this work.

\section{REFERENCES}

1. Cohen S, Bacon BR, Berlin JA, Fleischer D, Hecht GA, Loehrer PJ Sr, et al. National Institutes of Health Stateof-the-Science Conference Statement: ERCP for diagnosis and therapy. Gastrointest Endosc 2002;56:803-9. doi:10.1016/S0016-5107(02)70351-9

2. Chen WX, Zhang Y, Li YM, Xu GQ, Fang Y, Cai SP. Endoscopic retrograde cholangiopancreatography in evaluation of choledochal dilatation in patients with obstructive jaundice. Hepatobiliary Pancreat Dis Int 2002;1:111-3.

3. Mallery JS, Baron TH, Dominitz JA, Goldstein JL, Hirota WK, Jacobson BC, et al. Standards of Practice Committee, American Society for Gastrointestinal Endoscopy Complications of ERCP. Gastrointest Endosc 2003;57:633-8. doi:10.1016/S0016-5107(03)80005-6

4. Christensen M1, Matzen P, Schulze S, Rosenberg J. Complications of ERCP: a prospective study. Gastrointest Endosc 2004;60:721-31. doi:10.1016/S0016-5107(04)02169-8

5. Adler DG, Baron TH, Davila RE, Egan J, Hirota WK, Leighton JA, et al. Standards of Practice Committee of American Society for Gastrointestinal Endoscopy ASGE guideline: the role of ERCP in diseases of the biliary tract and the pancreas. Gastrointest Endosc 2005;62:1-8. doi:10.1016/j.gie.2005.04.015

6. Camp ER, Vogel SB. Blind Whipple resections for periampullary and pancreatic lesions.Am Surg 2004;70:6-10.

7. Jemaa Y, Houissa F, Trabelsi S, Moussa A, Belhouchet $\mathrm{H}$, Mouelhi L, et al. Endoscopic ultrasonography versus helical CT in diagnosis and staging of pancreatic cancer. Tunis Med 2008;86:346-9.

8. Agarwal B, Abu-Hamda E, Molke KL, Correa AM, Ho L. Endoscopic ultrasound-guided fine needle aspiration and multidetector spiral $\mathrm{CT}$ in the diagnosis of pancreatic cancer. Am J Gastroenterol 2004;99:844-50. 
doi:10.1111/j.1572-0241.2004.04177.x

9. Skordilis P, Mouzas IA, Dimoulios PD, Alexandrakis G, Moschandrea J, Kouroumalis E. Is endosonography an effective method for detection and local staging of the ampullary carcinoma? A prospective study. BMC Surg 2002;2:1-8. doi: 10.1186/1471-2482-2-1

10. Bakkevold KE, Arnesjø B, Kambestad B. Carcinoma of the pancreas and papilla of Vater: presenting symptoms, signs, and diagnosis related to stage and tumour site. Aprospective multicentre trial in 472 patients. Norwegian Pancreatic Cancer Trial. Scand J Gastroenterol 1992;27:317-25. doi: 10.3109/00365529209000081

11. Rivadeneira DE1, Pochapin M, Grobmyer SR, Lieberman MD, Christos PJ, Jacobson I, Daly JM. Comparison of linear array endoscopic ultrasound and helical computed tomography for the staging of periampullary malignancies. Ann Surg Oncol 2003;10:890-7. doi:10.1245/ ASO.2003.03.555

12. Irie $\mathrm{H}$, Honda $\mathrm{H}$, Shinozaki $\mathrm{K}$, Yoshimitsu $\mathrm{K}$, Aibe $\mathrm{H}$, Nishie A, et al. MR imaging of ampullary carcinomas. $J$ Comput Assist Tomogr 2002;26:711-7.

13. Domagk D, Wessling J, Reimer P, Hertel L, Poremba C, Senninger N, et al. Endoscopic retrograde cholangiopancreatography, intraductal ultrasonography, and magnetic resonance cholangiopancreatography in bile duct strictures: a prospective comparison of imaging diagnostics with histopathological correlation. Am J Gastroenterol 2004;99:1684-9. doi:10.1111/j.1572-0241.2004.30347.x

14. Rösch T, Meining A, Frühmorgen S, Zillinger C, Schusdziarra V, Hellerhoff $\mathrm{K}$, et al. A prospective comparison of the diagnostic accuracy of ERCP, MRI/MRCP, $\mathrm{CT}$, and EUS in biliary strictures. Gastrointest Endosc 2002;55:870-6. doi: 10.1067/mge.2002.124206

15. Malik S, Kaushik N, Khalid A, Bauer K, Brody D, Slivka A, et al. EUS Yield in Evaluating Biliary Dilatation in Patients with Normal Serum Liver Enzymes. Dig Dis Sci 2007;52:508-12. doi:10.1007/s10620-006-9582-6

16. Reddymasu SC, Gupta N, Singh S, Oropeza-Vail M, Jafri SF, Olyaee M. Pancreato-Biliary Malignancy Diagnosed by Endoscopic Ultrasonography in Absence of a Mass Lesion on Transabdominal Imaging: Prevalence and Predictors. Dig Dis Sci 2011;56:1912-6. doi:10.1007/ s10620-010-1511-z

17. Smith I, Monkemuller K, Wilcox CM. Incidentally Identified Common Bile Duct Dilatation: A Systematic Review of Evaluation, Causes, and Outcome. J Clin Gastroenterol. 2015;49:810-5. doi: 10.1097/MCG.0000000000000394

18. Wermke W, Schulz HJ. [Sonographic diagnosis of bile duct calculi. Results of aprospective study of 222 cases of choledocholithiasis]. Ultraschall Med 1987;8:116-20.

19. Pasanen PA, Partanen KP, Pikkarainen PH, Alhava EM, Janatuinen EK, Pirinen AE. A comparison of ultrasound, computed tomography and endoscopic retrograde cholangiopancreatography in the differential diagnosis of benign and malignant jaundice and cholestasis. Eur J Surg
1993;159:23-9.

20. Kaltenthaler E, Vergel YB, Chilcott J, Thomas S, Blakeborough $\mathrm{T}$, Walters $\mathrm{SJ}$, et al. A systematic review and economic evaluation of magnetic resonance cholangiopancreatography compared with diagnostic endoscopic retrograde cholangiopancreatography. Health Technol Assess 2004;8:1-89. doi.org/10.3310/hta8100

21. Soto JA1, Alvarez O, Múnera F, Velez SM, Valencia J, Ramírez N. Diagnosing bile duct stones: comparison of unenhanced helical CT, oral contrast-enhanced CT cholangiography, and MR cholangiography. AJR Am J Roentgenol 2000;175:1127-34. doi : 10.2214/ajr.175.4.1751127

22. Tseng CW, Chen CC, Chen TS, Chang FY, Lin HC, Lee SD. Can computed tomography with coronal reconstruction improve the diagnosis of choledocholithiasis? J Gastroenterol Hepatol 2008;23:1586-9.

23. Wu SD, Zhang ZH, Jin JZ, Kong J, Wang W, Li DY, et al. Effect of narcotic analgesic drugs on human Oddi's sphincter motility. World J Gastroenterol 2004;10:29014. doi:10.3748/WJG.v10.119.2901

24. Farahmand H, PourGholami M, Fathollah MS. Chronic Extrahepatic Bile Duct Dilatation: Sonographic Screening in the Patients with Opioid Addiction. Korean $J$ Radiol 2007;8:212-5. doi : 10.3348/kjr.2007.8.3.212

25. Sharma SS. Sphincter of Oddi dysfunction in patients addicted to opium: anunrecognized entity. Gastrointest Endosc 2002;55:427-30. doi: 10.1067/mge.2002.121600 